\title{
Older drivers' accident risk: Conceptual and methodological issues
}

Reprint from Accident Analysis and Prevention,

Vol. 30, No. 3, pp. 293-297, 1998

Liisa Hakamies-Blomqvist

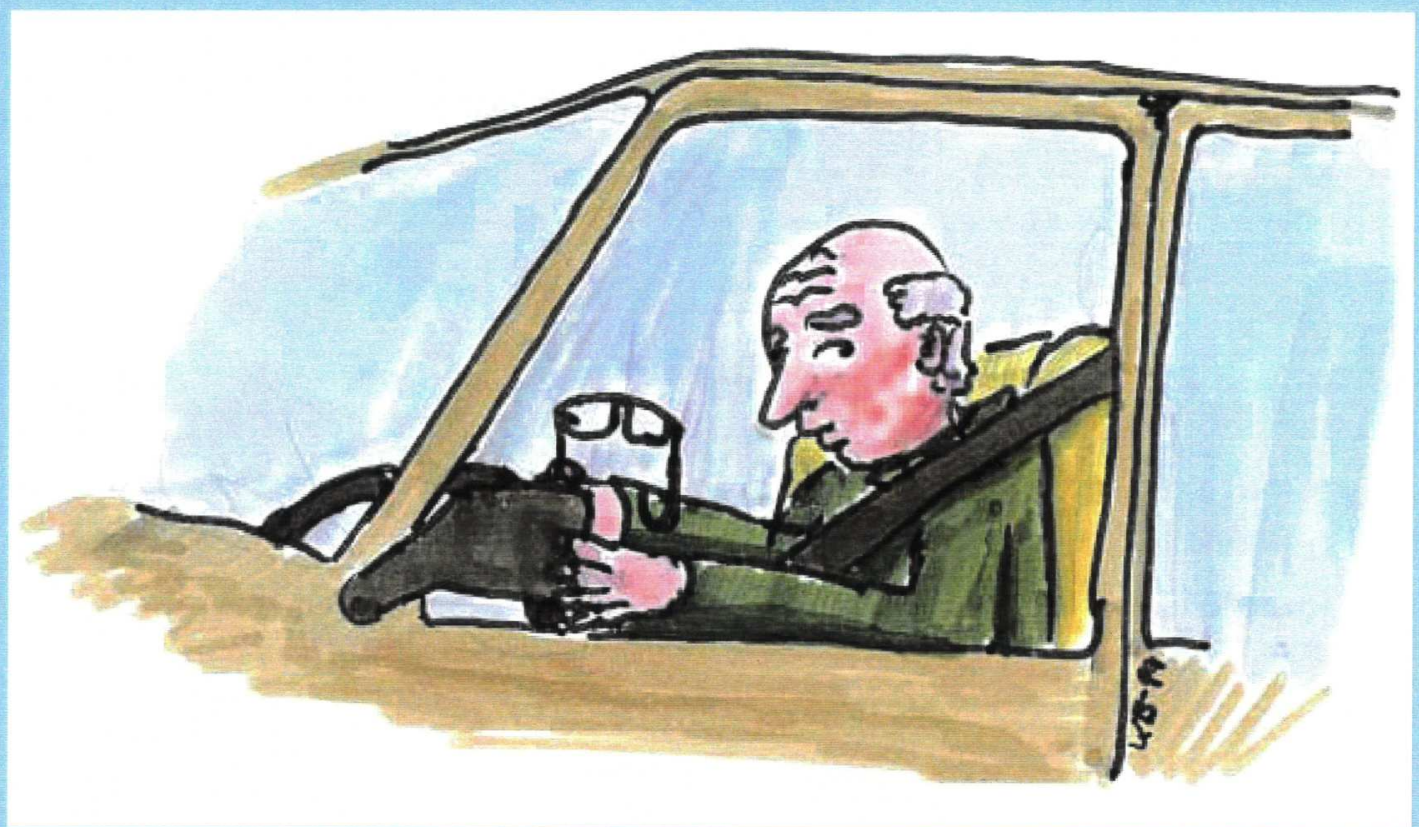




\section{Older drivers' accident risk: Conceptual and methodological issues}

Reprint from Accident Analysis and Prevention, Vol. 30, No. 3, pp. 293-297, 1998

Liisa Hakamies-Blomqvist 


\title{
OLDER DRIVERS'ACCIDENT RISK: CONCEPTUAL AND METHODOLOGICAL ISSUES
}

\author{
LiISA HAKAMIES-BLOMQVIST ${ }^{1,2, *}$ \\ ${ }^{1}$ Department of Psychology, P.Box 13, University of Helsinki, FIN-00014 Helsinki, Finland \\ and ${ }^{2}$ Swedish National Road and Transport Research Institute (VTI), SE-58195 Linköping, Sweden
}

\begin{abstract}
This paper discusses the concepts of age and risk, and some methodological pitfalls inherent in the different ways of estimating older drivers' accident risk. (C) 1998 Published by Elsevier Science Ltd. All rights reserved
\end{abstract}

Keywords - Accident, Crash, Exposure, Older driver, Risk

\section{INTRODUCTION}

Research on aging and automobile driving has a history reaching back to the 1930's. In those early days concern was expressed about the steadily increasing proportion of drivers over 40 years of age, and the conclusion was that they should be given "objective facts about their failing abilities and how to offset them" (DeSilva, 1938). Most of the drivers who were over 40 years of age in 1938 are not driving among us anymore, but it is still generally agreed that the industrialized countries have, or are soon going to have, an 'older driver problem'. This problem is seen as the result of the increasing number of older drivers in the traffic system, and their higher than average accident risk. During the last decades, research on older drivers has flourished. Because of the obvious social demand, mainstream older driver research has focused on practical problems, rather than on conceptual and methodological issues.

\section{'OLDER DRIVERS'” RISK}

'Aging' is a multidimensional concept that is so hard to define in a scientific context that, indeed, most authors do not even bother to try. According to Birren and Cunningham (1985), on the multidisciplinary field of gerontology, biological scientists define the term most often, psychologists rarely, and social scientists almost never. Among traffic researchers, the word 'age' is practically always understood in its purely chronological sense, i.e. as time elapsed since birth, ignoring alternative or complementary

${ }^{*}$ Corresponding author. Tel.: + 1358 19123403; Fax: +1 358 19123404. biological, psychological, or social definitions. The chronological age variable is mainly used as an index or dummy variable for classification purposes without further reference to the host of underlying processes it stands for. Such a straightforward approach to the concept of age makes measurement issues relatively easy; its cost is, however, that it becomes very hard to define in a satisfactory way when one becomes an 'older driver'. Focusing on the psychological expressions of aging, the transition to the 'older driver' group could, at least in theory, be defined by changes in a number of important performance variables. In biological terms, closeness to death rather than length of elapsed life could be a classification variable with some content validity (with the practical drawback, of course, that its use would mostly be limited to retrospective designs). On the chronological dimension, in contrast, there are no valid grounds for marking any specific point as the transition point. Although the probability of older-driver-like characteristics increases with age, aging patterns differ greatly among individuals (Rabbitt, 1993). Some drivers will attain any theoretical threshold values in early middle age while a few may continue as middleaged-like drivers up to their second century.

\section{OLDER DRIVERS' 'RISK'}

When reference is made to older drivers' 'higher accident risk', risk calculations are based on some operative variant of the equation Risk = Accidents/ Exposure. Depending on what kind of risk the authors are interested in, the numerator and the denominator can be expressed in different measurable entities. Often, the chosen interpretation of the concept of risk is not explicitly stated: instead of specify- 
ing whether they are interested in risk in the sense of individual accident proneness, or of expectancy of societal costs, or of something else, many authors leave this for the reader to deduce on the basis of their methodological choices.

In the risk equation, it is generally agreed that the numerator poses less problems than the denominator. There are reliable sources of information concerning accidents, e.g. computerized databases kept by different authorities, containing all reported accidents corresponding to a predefined set of inclusion criteria. Within these databases, the accidents of different driver groups may not be similar samples of their total number of accidents, if the probability of an accident's being reported varies among the groups, or if the inclusion criteria are met more frequently by some group's accidents than by others. For older drivers, the best known source of this type of sampling bias is the aging organism's greater physical frailty. This is especially true for databases involving injury but may also affect those including 'all' accidents if higher injury rates lead to higher overall reporting rates. Generally speaking, the more the inclusion of an accident in the database is dependent on the seriousness of the outcome, the more overestimated will any calculated increase in age-related risk be. As demonstrated by Evans (1991), a graph showing a marked increase in older drivers' fatality rates flattens considerably when fatalities are replaced by crashes of sufficient severity to kill 80-year-old male drivers. According to Maycock (1997), half of the increased fatality risk of drivers aged 75 years or more, compared to drivers aged 30 years, might be due to the enhanced susceptibility of the older drivers to be killed in the accidents in which they are involved, rather than to their higher accident rates. Estimates of age related increase of risk should therefore always be accompanied by a discussion of a possible sampling bias in the numerator.

As to the denominator of the risk equation, while opinions about the basic meaning of the concept of exposure seem rather convergent, there is no consensus about its exact definition, and the approaches to its measurement diverge greatly. In the present context, i.e. when comparing different driver groups' accident risk, any metric of exposure could reasonably be required to fulfill two criteria: (1) it should be relevant for the intended concept of risk, and (2) the entity measured should be the same for all the groups.

In age comparisons, the choice of the denominator in the risk equation has resulted in very different findings. In the late 1960s and early 1970s, it was settled that the older drivers in the U.S. had less accidents per capita and per driver license, but more accidents per mileage than others (Planek, 1972). This finding has later been repeatedly replicated (see, e.g., Evans, 1991; Massie and Campbell, 1993). If risk is understood as expected societal costs caused by a given age group, accidents per population is an adequate measure. If, however, population-related accident rates result in conclusions not only concerning a group's general public safety impact but also concerning its member drivers, these conclusions will be biased. Because of the varying driver/population ratio in different age groups, the exposure metric will not be the same for all groups.

To overcome this difficulty, the number of driver licenses is often used as exposure measure, on the assumption that the number of driver licenses is a reasonable estimate of the number of active drivers. For this assumption to be equally valid for the different groups under comparison, the necessary conditions for license holding should not differ between them. Any legal obligations connected to a driver group's maintaining a valid license will affect the group's active drivers/licensed drivers ratio. For instance, in Finland, drivers aged 70 years or more have to renew their license periodically, while Sweden has no age-related controls. As the renewal requires a heavy and costly procedure, older Finnish persons who do not drive, or who drive very little, tend to give up their license, while in Sweden licenses are mostly kept for life. Not surprisingly, while population-related comparisons between the two countries show similar age trends in accident rates, comparisons using driver licenses as exposure measure show a sharp and alarming rise for the older Finns, starting at the age of 70 years - not because of a rise in the number of accidents but because of a fall in the number of licensed drivers (Hakamies-Blomqvist et al., 1995, 1996).

When risk is understood in the sense of individual accident tendency, it is generally felt that a 'hard' estimate of the actual amount of driving, e.g. mileage driven, is needed. However, the relationship between yearly mileages and accident rates per mile is not linear: high mileage drivers have, independently of age, lower accident rates per mile than low mileage drivers. Since older drivers typically drive less, their risk will be overestimated when based on mileage (for a review, see Janke, 1991). There is some evidence supporting the claim that older drivers' voluntary, compensatory limiting of driving exposure has a positive safety effect (Hakamies-Blomqvist, 1994). However, as pointed out by Maycock, such compensatory behavior has at the same time "the perverse effect of increasing their per kilometer accident rate" (Maycock, 1997). One way of attenuating the bias inherent in distance based exposure estimates is to 
use time in traffic as a competing 'hard' measure of exposure. In a Canadian study combining accident data with survey data providing both kinds of exposure measures, time based measures resulted in lower risk estimates for older drivers than distance based (Chipman et al., 1992, 1993). In their conclusions, the authors recommend a combined use of both.

Because of the practical difficulties and high cost of acquiring reliable and unbiased 'hard' exposure data, an alternative technique has been developed in which the exposure estimate is induced from the accident database itself (for a review, see Stamatiadis and Deacon, 1997). Quasi-induced exposure technique has mostly been used on data consisting of 'clean' multiple-vehicle accidents, i.e. collisions in which legal responsibility has been entirely assigned to one of the parties involved. The technique relies on the assumption that the drivers at fault in collision accidents pick their collision partners at random; consequently, the sample of not responsible drivers is a representative sample of the drivers in the system, i.e. exposure. For this key assumption to be valid, the probability that a driver is hit as innocent victim should depend exclusively on his/her presence in the traffic flow. In other words, the outcome of a potential accident situation should be unrelated to the behavioral characteristics of the innocent victims in posse or in esse. In reality, this is mostly not the case. While the attributions of legal responsibility for practical reasons tend to be categorical, the probability that a given conflict situation results in a collision accident is in general dependent of the behavior of both parties. Consequently, the exposure metric is not necessarily the same for different driver groups, since it may reflect different combinations of physical presence and driving behavior. A driver group with slow and safe driving style may actually get worse risk estimates because they manage to avoid being hit (Janke, 1991; Lyles and Stamatiadis, 1991). If accident proneness is defined as "the inclination not to compensate", as suggested by Haight (1986), we have limited use for an exposure metric that results in lower risk estimates for accident prone drivers with less defensive driving style, and consequently more frequently incurring collisions as 'innocent' parties, while older drivers who compensate for their agerelated weaknesses by adopting a more cautious driving style are rewarded for this by higher risk estimates.

In the same vein as Evans (1991) who chose to base calculations of age related risk on crashes of sufficient severity to kill 80 -year-old male drivers rather than fatalities, induced exposure metric could be made similar for all driver groups despite different behavioral characteristics by changing the sample.
Ideally, the sample should include not only collision accidents but also those conflict situations that would have led to collisions given some standard behavior of the not responsible party. Such a metric would eliminate the behavioral source of error, but it would have to be based on suitable observational data on traffic conflicts. This does not seem very practical, since the central purpose of induced exposure technique was to manage risk estimation without independent empirical exposure measures. As an alternative solution for unbiased comparisons between different driver groups, the induced exposure term could (at least in theory) be corrected for those behavioral characteristics that supposedly affect the drivers' probability of being hit or avoided when about to become innocent victims in an accident. Unfortunately, such information is not readily available either.

In conclusion, it seems inevitable that cautious driver groups like older drivers, with defensive driving style and generally lower speeds, will get inflated risk estimates in risk calculations based on induced exposure. The magnitude of the error will vary depending on how the sample of accidents is limited as to place, time, or accident type. In head-on collisions between vehicles having high speed, the possibilities of the innocent victim to avoid the accident are quite limited and the bias therefore presumably small. In contrast, if the analysis is limited to, say, intersection collisions in urban area, the driving speed and style of the innocent victim may be decisive to whether or not an accident can be avoided, and the risk estimates of older drivers therefore considerably inflated. As a general recommendation, any analysis using induced exposure should be accompanied by a discussion of how, due to the nature of the accident database, the behavioral source of error may affect the exposure estimates.

\section{WHOSE RISK IS 'OLDER DRIVERS' RISK?'}

Let us assume that all the problems presented above have been solved: that we have specified a relevant interpretation of the concept of risk, and have adequately chosen the corresponding operationalizations of accidents and exposure. We still have one serious methodological dilemma, since the risk estimate we get is the average risk of the age group: how should we interpret this 'average risk', i.e. to whom should it be attributed? The importance of this problem increases with the age of the studied populations. Since findings from experiments in cognitive gerontology consequently show an age related increase in interindividual variance among healthy 
older subjects (Kausler, 1991), variance in individual accident risk, accentuated by illness related performance deficiencies, must be even higher. The distribution may indeed be bimodal rather than normal; in virtue of their cautious driving style and self-critical attitude, many older persons are extremely safe drivers, while certain pathological subgroups will have functional decrements leading to considerable risk increase.

In response to this last concern, the focus of older driver research has during the last decade shifted from a general approach toward a differential one. While earlier research mostly was guided by the question "Why do older drivers have higher accident risk?" the alternative question "Which older drivers have higher accident risk?" has gained momentum in the 1990s. An increasing number of research efforts have concentrated on subgroups of older drivers having illnesses that can affect abilities essential for car driving. Of such illnesses, dementia of Alzheimer type has received most attention. It has been repeatedly shown that a driver's accident risk increases as a consequence of even a slight cognitive decline related to the slow onset of a dementing illness (for a bibliography, see Johansson and Lundberg, 1997). More research will be needed, however, before it is possible to estimate what portion of older drivers' average risk increase is attributable to certain pathological subgroups rather than to 'normal' older drivers. The question is somewhat problematic on a conceptual level, too, since opinions vary greatly among gerontologists as to what constitutes 'normal' aging as opposed to 'pathological'-some claim that it is not legitimate to make such a conceptual distinction at all.

Until the beginning of the differential trend in older driver research, findings concerning the age related risk increase and changes in accident patterns were most often explained ad hoc by referring to seemingly relevant findings from cognitive gerontology. When a plausible hypothetical explanation has been repeated in a sufficient number of studies there is a risk that it gets consolidated without ever having been tested. In this manner, the typical intersection accidents have been speculatively attributed to declines in attention and visual field deficits so often that the relation between these functional declines and risk increase in intersections almost seems thereby proved. However, not all age related performance decrements that appear to be relevant for safe driving actually lead to decreased safety. The patterns of covariance between chronological age, functional declines, and unsafe driving may not correspond to our a priori conceptions. It is possible, for instance, that declines in visual attention have strong relations only with risk increase in individuals with beginning dementia, whereas in others with intact judgment their effect may be compensated for. In future diagnostic research, it would be important to study not only easy-to-test cognitive functions but also potentially important mediating variables like judgment or emotional stability. When further advances are made in research relating differential patterns of aging to success as driver, there will be better grounds to recommend strategies of screening and restraining for certain older driver groups, while supporting the continued driving activity of others.

\section{THE FUTURE OF THE 'OLDER DRIVER PROBLEM'}

We still do not know enough about the cohortand time-related aspects of older drivers' accident risk, nor of their cognitive decrement epidemiology, to be able to produce reliable prognoses about their accident rates in the next few decades. In addition, there may be system effects that are not directly predictable on the basis of the current situation. A sizeable increase of the portion of older drivers in the traffic system may force the system to adapt towards their needs in an unanticipated manner. According to Smeed's 'law', the first few private cars in a country have high fatality rates per car, and with increasing car density, the fatality risk per car goes down (Smeed, 1968). On a level of abstraction high enough to be purely speculative, if a similar 'unit density law' applies to older drivers, then the 'driving granny lethality index' might go down as a consequence of the increase in 'driving granny rates'. For this to be possible, not only the traffic environment would have to be increasingly adapted to older drivers' needs, but the patterns of interaction among all the participants of the traffic system would probably need to change, in response to the greater probability of having to interact with an older driver.

\section{REFERENCES}

Birren, J. E. and Cunningham, W. R. (1985) Research in the psychology of aging: Principles, concepts, and theory. In Handbook of the Psychology of Aging, eds J. E. Birren and K. W. Schaie, 3rd edn, pp. 3-34. Academic Press, San Diego.

Chipman, M. L., MacGregor, C. G., Smiley, A. M. and Lee-Gosselin, M. (1992) Time vs. distance as measures of exposure on driving surveys. Accident Analysis and Prevention 24, 679-684.

Chipman, M. L., MacGregor, C. G., Smiley, A. M. and Lee-Gosselin, M. (1993) The role of exposure in comparisons of crash risk among different drivers and driving environments. Accident Analysis and Prevention 25, 207-211. 
DeSilva, H. R. (1938) Age and highway accidents. Scientific Monthly 47, 536-545.

Evans, L. (1991). Traffic Safety and the Driver. Van Nostrand Reinhold, New York.

Haight, F. A. (1986) Risk, especially risk of traffic accident. Accident Analysis and Prevention 18, 359-366.

Hakamies-Blomqvist, L. (1994) Compensation in older drivers as reflected in their fatal accidents. Accident Analysis and Prevention 26, 107-112.

Hakamies-Blomqvist, L., Johansson, K. and Lundberg, C. (1995) Driver licenses as a measure of older drivers' exposure: A methodological note. Accident Analysis and Prevention 27, 853-857.

Hakamies-Blomqvist, L., Johansson, K. and Lundberg, C. (1996) Medical screening of older drivers as a traffic safety measure-A comparative Finnish-Swedish evaluation study. Journal of the American Geriatrics Society 44, 650-653.

Janke, M. K. (1991) Accidents, mileage, and the exaggeration of risk. Accident Analysis and Prevention 23, 183-188.

Johansson, K. and Lundberg, C., The 1994 International Consensus Conference on Dementia and Driving: A brief report. Alzheimer's Disease and Associated Disorders 11, Suppl. 1, 62-69. (1997)
Kausler, D. H. (1991) Experimental Psychology, Cognition, and Human Aging, 2nd edn. Springer, New York.

Lyles, R. W. and Stamatiadis, P. (1991) Quasi-induced exposure revisited.. Accident Analysis and Prevention 23, 275-285

Massie, D. and Campbell, K. (1993) Accident involvement rates by age and gender. UMTRI Research Review 23, $1-13$.

Maycock, G. (1997) The Safety of Older Car-Drivers in the European Union. AA Foundation for Road Safety Research, Basingstoke.

Planek, T. W. (1972) The aging driver in today's traffic: a critical review. In Aging and Highway Safety: The elderly in a mobile society, eds T. W. Planek, W. A. Mann and E. L. Wiener, Vol. 7, pp. 1-38. North Carolina Symposium on Highway Safety, Chapel Hill, NC.

Rabbitt, P. (1993) Does it all go together when it goes? The nineteenth Bartlett Memorial Lecture. Quarterly Journal of Experimental Psychology 46A, 385-434.

Smeed, R. (1968) Variations in the patterns of accident rates in different countries and their causes. Traffic Engineering and Control 10, 364-371.

Stamatiadis, N. and Deacon, J. A. (1997) Quasi-induced exposure: Methodology and insight. Accident Analysis and Prevention 29, 37-52. 
VI FORSKAR FÖR ETT LIV I RÖRELSE

Statens väg- och transportforskningsinstitut (VTI) har kompetens och laboratorier för kvalificerade forskningsuppdrag inom transporter och samhällsekonomi, trafiksäkerhet, fordon, miljö samt för byggande, drift och underhăll av vägar och järnvägar.

The Swedish National Road and Transport Research Institute (VTI) has laboratories and know-how for advanced research commissions in transport and welfare economics, road safety, vehicles and the environment. It also has research capabilities for the construction, operation and maintenance of roads and railways.

\section{Adress}

Postal address

SE-581 95 Linköping, Sweden
Telefon

Telephone

Nat 013-20 4000

Int +4613204000
Fax

E-post

E-mail

Nat 013-14 1436

Int +4613141436 